\section{Estudio integral de los recursos hídricos y las coberturas del suelo de la cuenca media y baja del río Sauce Grande (Argentina)}

Tesis de Doctorado en Geografía

\author{
Autora: Andrea Soledad Brendel \\ Universidad Nacional del Sur/Consejo Nacional \\ de Investigaciones Científicas y Técnicas
}

@ [ asbrendel@iado-conicet.gob.ar ]

Directores: Dra. María Cintia Piccolo y Dr. Gerardo M.E. Perillo

Universidad Nacional del Sur

Fecha de defensa: marzo de 2020

DOI: http://dx.doi.org/10.19137/huellas-2020-2425

$\mathrm{L}$ as cuencas hidrográficas constituyen un sistema en donde interactúan factores naturales como la geomorfología, el clima, el suelo, el agua, la vegetación y la fauna, en conjunto con los desarrollos productivos generados por el hombre (Gil, 2009). El uso del suelo y la variabilidad climática son los principales factores que afectan la hidrología y la dinámica ambiental de las mismas (Molina-Navarro et al., 2014). El objetivo general de la investigación fue realizar un estudio integral de los recursos hídricos y las coberturas del suelo de la cuenca del río Sauce Grande. Para ello, se propuso, analizar el efecto de la variabilidad pluviométrica sobre la cobertura de agua y la morfometría de los principales recursos hídricos de la cuenca, como así también evaluar el comportamiento espacio-temporal de los parámetros limnológicos y establecer su relación con las actividades antrópicas y la topografía. Finalmente, se estudiaron por un lado, las series de tiempo en alta frecuencia del caudal del río Sauce Grande en función de registros de precipitación diarios y por el otro, los datos meteorológicos y limnológicos registrados en alta frecuencia por una boya de monitoreo con la finalidad de interpretar la dinámica hidrometeorológica de la laguna Sauce Grande.

El área de estudio fue la cuenca hidrográfica del río Sauce Grande $\left(4856 \mathrm{~km}^{2}\right)$, localizada al sur de la Región Pampeana, Argentina (Figura $\mathrm{N}^{\circ} 1$ ). Es exorreica y a lo largo de su extensión presenta dos cuerpos de agua principales: el dique Paso de Las Piedras (DPP) y la laguna Sauce Grande (LSG) (Figura $\mathrm{N}^{\circ} 1$ ). El primero es fuente de agua potable para 500.00 habitantes y también para uso de las actividades industriales del polo industrial ubicado en la ciudad de Bahía Blanca. En la LSG el principal atractivo turístico es la pesca deportiva.

Inicialmente, se analizaron las anomalías de las principales variables meteorológicas, utilizando una extensa serie de tiempo (1960-2017) de tres estaciones meteorológicas ubicadas en el área de influencia de la cuenca. Los resultados indicaron que en la totalidad del área de estudio, la temperatura media aumentó, mientras que la velocidad del viento disminuyó. La tendencia de la precipitación fue espacialmente heterogénea dado que aumentó en el norte y sur y disminuyó en el centro. Este parámetro, se estudió en función de la variación espacio-temporal de la cobertura de agua del DPP y la LSG durante el período 1987-2017. Para calcular el área de los mismos se procesaron imágenes satelitales Landsat 5 TM, Landsat 7 ETM+ y Landsat 8 OLI-TIRS. Los resultados arrojaron que el área de estos dos cuerpos de agua y la precipitación presentaron una asociación lineal positiva, alta y estadísticamente significativa, indicando que la precipitación es la variable más importante en las fluctuaciones del área de los mismos. 
Figura $N^{\circ}$ 1. Localización de la cuenca del río Sauce Grande y de las estaciones meteorológicas y limnológicas analizadas
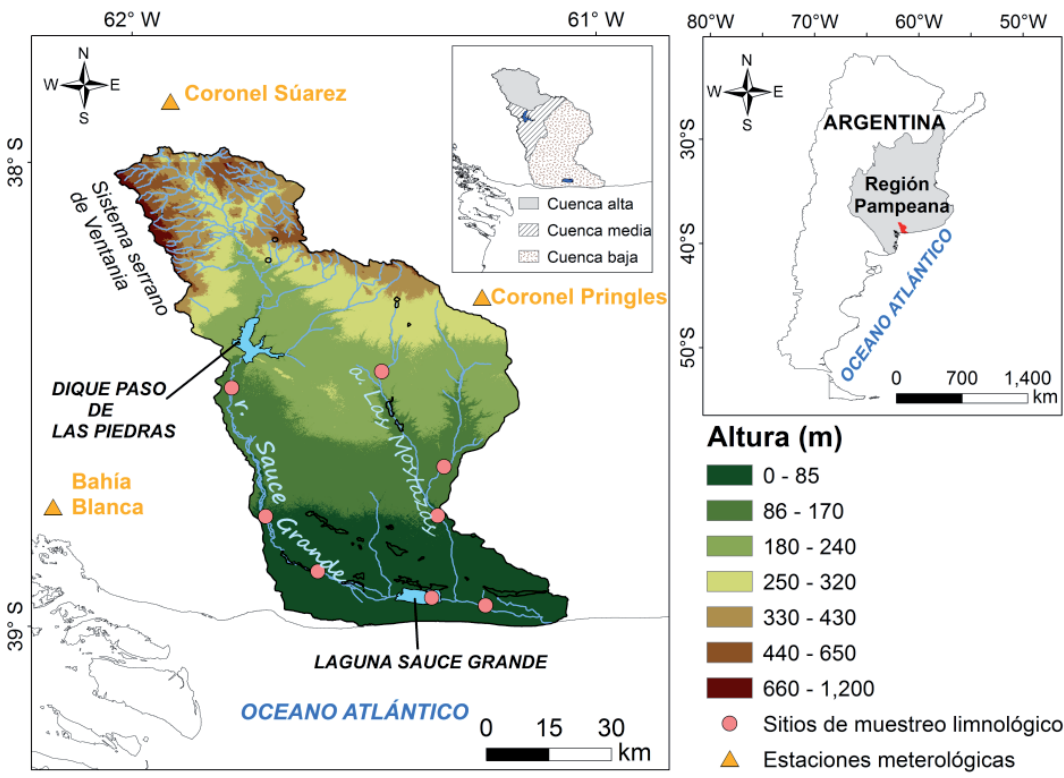

Fuente: elaboración propia.

El caudal del río Sauce Grande (20162018) fue medido en alta frecuencia (10 minutos) en dos sectores del río. Para ello, se instalaron dos estaciones limnimétricas y se realizaron cinco campañas de aforo, utilizando un perfilador de corrientes acústico Doppler (Figura $\mathrm{N}^{\circ} 2$ ). Como resultado, se encontró que el flujo del río fluctuó en función de la variabilidad pluviométrica. Las áreas inundables ante un evento de precipitación intenso se ubicaron en los médanos costeros y en los sectores cercanos al ingreso del río en la laguna homónima. Este cuerpo de agua también fue monitoreado a partir de la instalación de una boya con sensores en alta frecuencia (i.e. nivel del agua, conductividad eléctrica, temperatura del aire) durante 2016-2018 (Figura $N^{\circ}$ 2). Los resultados permitieron evaluar la dinámica de las variables hidrometeorológicas medidas en un período de mayor profundidad de la laguna y compararlos con un estudio previo realizado durante un período de sequía (febrero de 2011-enero de 2012) (Fornerón, 2012). En esta tesis, además de aumentar el nivel del agua en relación con un período seco, se registró un aumento de la temperatura del agua y del aire, como así también, una disminución de la conductividad eléctrica y la velocidad del viento. Tras la aplicación de la Trasformada Rápida de Fourier a los datos registrados por la boya, se detectó que la LSG presenta una circulación atmosférica local de origen geomorfológico. Además, la brisa de mar generada en la costa de Monte Hermoso (ubicada a 6 $\mathrm{km}$ de la laguna) ingresa en la LSG y provoca cambios en la temperatura del aire y en la velocidad y dirección del viento de la laguna. 
Figura $\mathbf{N}^{\circ}$ 2. Localización y características de los dispositivos en alta frecuencia utilizados
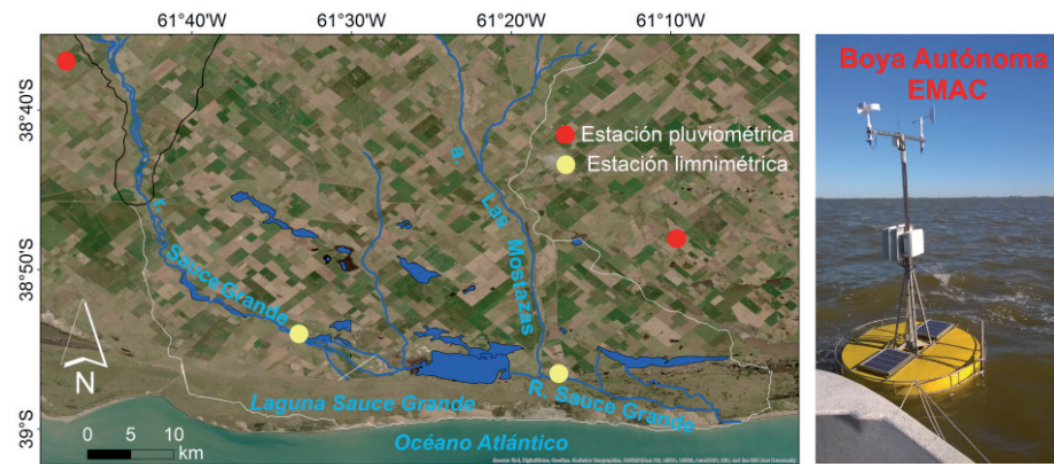

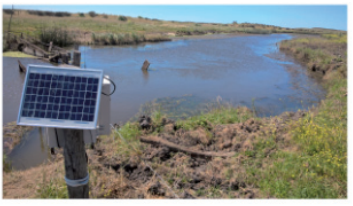

Estación limnimétricas EMAC

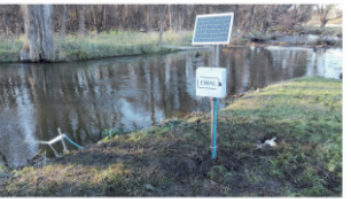

Perfilador de corrientes acústico Doppler

Fuente: elaboración propia

Por otro lado, se midieron parámetros limnológicos (i.e. materia orgánica particulada, oxígeno disuelto, nutrientes) en los cursos de agua de la cuenca media y baja del río Sauce Grande durante el año 2016 (Figura $N^{\circ}$ 1). Según el comportamiento espacio-temporal de las variables medidas, este sector de la cuenca presentó tres unidades o grupos. A su vez, mostraron una marcada variación espacio-temporal. Por ejemplo, la conductividad eléctrica fue mayor en la laguna y en el sitio cercano a la descarga del río en el Océano Atlántico, dado que al ser los sectores de menor altura se genera la acumulación de sales provenientes de toda la cuenca. Estacionalmente, esta variable fue mayor en el otoño, producto del incremento de las precipitaciones. Los nutrientes fueron máximos durante el invierno y la primavera, producto probablemente de la aplicación de fertilizantes en la siembra y maduración de los cultivos de invierno.
Por otro lado, se clasificaron las coberturas del suelo en las tres áreas geomorfológicas de la cuenca (Figura $\mathrm{N}^{\circ}$ 3) Para ello, se consideraron dos conjuntos de muestras espaciales. Una resultante del procesamiento de las bandas del satélite Landsat 8 OLI-TIRS y su validación mediante encuentras a productores agropecuarios y la otra, compuesta por la toma de firmas espectrales a campo y el cálculo de seis índices espectrales de las imágenes satelitales Landsat 8 OLI-TIRS. Se utilizaron seis métodos de clasificación supervisados y dos no supervisados. El método de mayor precisión en la llanura fue el de Máxima Verosimilitud, mientras que en el médano y en el afloramiento rocoso fue la Distancia de Mahalanobis (Figura $\mathrm{N}^{\circ}$ 3). En todos los casos, la utilización de los índices espectrales mejoró significativamente la discriminación de las coberturas del suelo en comparación con el uso de la reflectividad de las bandas (Figura $\mathrm{N}^{\circ} 3$ ). A partir de la selección del 
mejor método y conjunto de datos para su determinación, se realizó un análisis multitemporal de las coberturas del suelo durante el período 2000-2016 (Figura $\mathrm{N}^{\circ}$ 4). Las cubiertas de vegetación (particularmente los cultivos) y el agua fluctuaron en función de los montos de precipitación (Figura $\mathrm{N}^{\circ} 3 \mathrm{~b}$ ). topográficas, hídricas y edáficas. Luego, se realizó el cruce de los dos productos cartográficos y se identificaron distintos niveles de vulnerabilidad eco-ambiental: muy bajo, bajo, medio, alto y muy alto (Figura $\mathrm{N}^{\circ} 4$ ). Se encontró que la cuenca del río Sauce Grande presentó cinco niveles de vulnerabilidad eco-ambiental. El

Figura $N^{\circ}$ 3. Variación espacio-temporal de las coberturas del suelo y su precisión en las tres áreas geomorfológicas de la cuenca del río Sauce Grande: afloramiento (a-d), llanura (b-e) y médano (c-f) durante el período 2001-2016
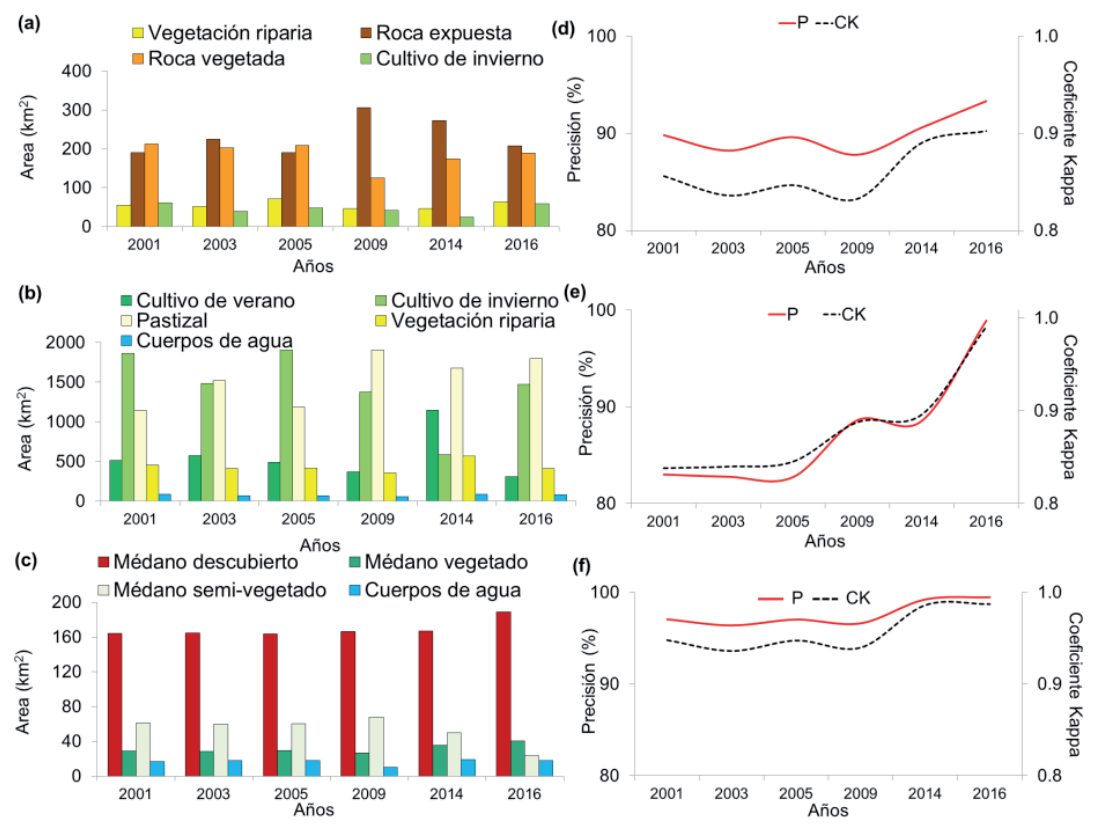

Fuente: elaboración propia.

Posteriormente, para integrar todos los resultados encontrados, se realizó un análisis de la vulnerabilidad eco-ambiental de la cuenca. Para ello, se realizó el cruce de dos mapas. Uno que presentó las coberturas del suelo medidas in situ (Figura $\mathrm{N}^{\circ} 3$ ) y otro que mostró las coberturas del suelo óptimas de la cuenca. Para determinar estas últimas, se establecieron condiciones lógicas a partir del análisis de variables climáticas, geomorfológicas, más frecuente fue el bajo $\left(1343,7 \mathrm{~km}^{2}\right)$, seguido del alto $\left(1091,4 \mathrm{~km}^{2}\right)$ (Figura $\mathrm{N}^{\circ}$ 4). La importancia de considerar esta última categoría es que las áreas de pastizales se utilizan para la implantación de cultivos, por lo que su conservación es fundamental dado la significativa provisión de bienes y servicios ecosistémicos que estos brindan. Los niveles muy altos y medios fueron menos frecuentes, pero las problemáticas que en estos espacios se generan 
Figura $\mathbf{N}^{\circ}$ 4. Niveles de vulnerabilidad eco-ambiental en la cuenca del río Sauce Grande

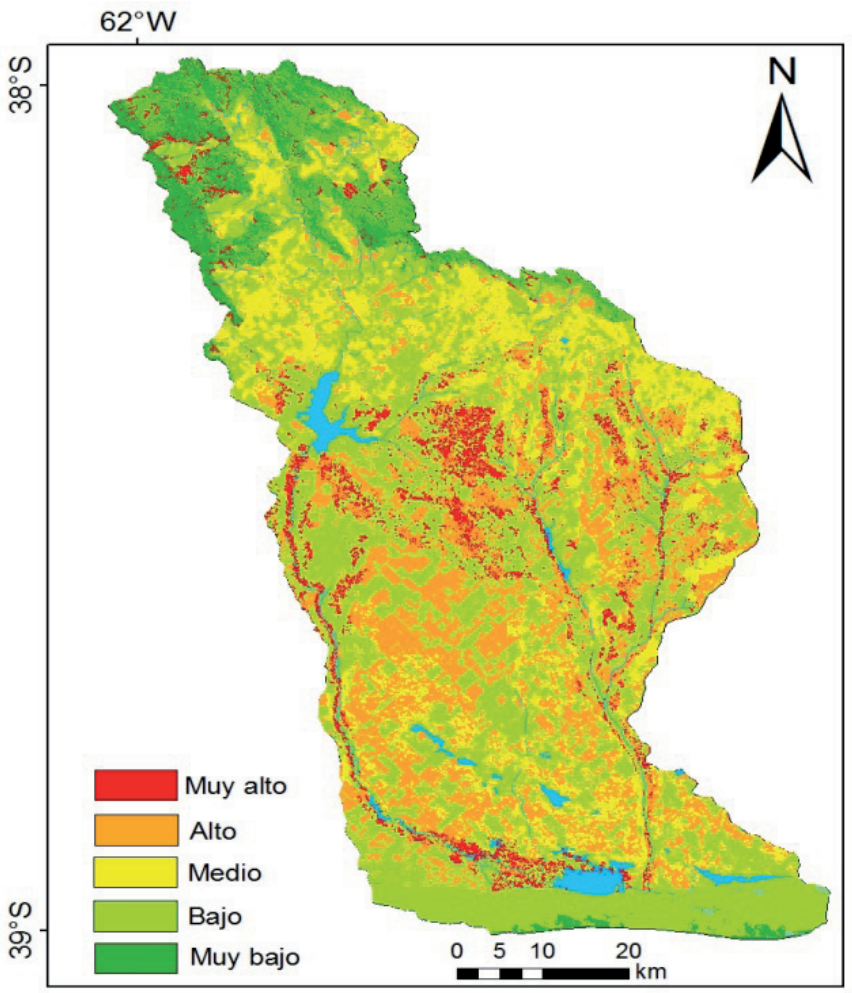

Fuente: elaboración propia.

son importantes, dado que los cultivos y pastizales se realizan sobre áreas inundables (Figura $\mathrm{N}^{\circ} 4$ ). En el primer caso podría generar graves consecuencias económicas a los productores agropecuarios, mientras que en el segundo, el recurso suelo está sobreexplotándose por el incremento de la superficie destina a cultivos. Teniendo en cuenta estos niveles y sus problemáticas socio-ambientales asociadas, se diseñaron estrategias de manejo sustentable del territorio que tuvieron como objetivo mejorar la calidad ambiental de la cuenca, considerando la sostenibilidad ambiental, social y económica. Por ejemplo, en las áreas con nivel de vul- nerabilidad muy alto (cultivos y pastizales se realizan sobre áreas indudables), se propone implementar en el campo señales y/o carteles para reconocer las áreas anegables y ayudar a reducir el riesgo, fundamentalmente agropecuario, mientras que en las de nivel alto (cultivos en áreas óptimas para pastizal), incentivar económicamente a los productores agropecuarios para fomentar la producción de pastizales naturales para ganadería extensiva. En las áreas con nivel medio, informar a los productores agropecuarios y a las autoridades de toda la cuenca las problemáticas ambientales y económicas que genera la sobreexplotación del recurso suelo. Se 
propone preservar los pastizales con el objetivo de mantener la biodiversidad en aquellas áreas con nivel de vulnerabilidad baja, mientras que el diseño de medidas de protección de las ciudades que están ubicadas en espacios con gran pendiente, como ocurre en la cuenca alta, en las áreas nivel de vulnerabilidad muy bajo.

\section{Referencias bibliográficas}

Fornerón, C.F. (2012). Hidrografia de la laguna Sauce Grande (provincia de Buenos Aires) en época de sequía (Tesis de Doctor en Geografía) Universidad Nacional del Sur, Departamento de Geografía y Turismo, Bahía Blanca.

Gil, V. (2009). Hidrogeomorfología de la cuenca alta del río Sauce Grande aplicada al peligro de Crecidas. (Tesis de Doctor en Geografía) Universidad Nacional del Sur, Departamento de Geografía y Turismo, Bahía Blanca.

Molina-Navarro, E., Trolle, D., Martínez-Pérez, S., Sastre-Merlín, A. \& Jeppesen, E. (2014). Hydrological and water quality impact assessment of a Mediterranean limno-reservoir under climate change and land use management scenarios. Journal of Hydrology, 509, 354-366. 